\title{
Rebuilding Walls: Market Transition and Social Mobility in the Post-Socialist Societies of Europe
}

\author{
Michelle Jackson, ${ }^{a}$ Geoffrey Evans ${ }^{b}$
}

a) Stanford University; b) University of Oxford

Abstract: We ask whether the transition from socialism to the market is consequential for social mobility, and, by implication, the permeability of class structures. While the short-term effects of market transition on patterns of social mobility have been documented for a small number of countries, we are able to examine the long-term effects of market transition for a group of 13 central and eastern European (CEE) countries. Only in the longer term can we properly appreciate the settled effects of transition on the distribution of resources, the organization of class and economic structures, and the transmission of inequalities across generations. We use data drawn from nationally representative cross-national surveys of CEE countries to compare patterns of social mobility in the early 1990s with those in the late 2000s. We find a significant decline in relative social mobility between the two periods and show that this decline is a consistent feature of mobility patterns across the region. We argue that changes in the institutions that regulate the transfer of capital across generations are likely to explain why the move from socialism to the market is associated with declining levels of social fluidity.

Keywords: social mobility; market transition; central and eastern Europe

Citation: Jackson, Michelle V., and Geoffrey Evans. 2017. "Rebuilding Walls: Market Transition and Social Mobility in the Post-Socialist Societies of Europe." Sociological Science 4: 54-79.

Received: July 11, 2016

Accepted: November 7, 2016

Published: January 16, 2017

Editor(s): Kim Weeden

DOI: $10.15195 / \mathrm{v} 4 . \mathrm{a3}$

Copyright: (C) 2017 The Author(s). This open-access article has been published under a Creative Commons Attribution License, which allows unrestricted use, distribution and reproduction, in any form, as long as the original author and source have been credited. (C) (i)
$\mathrm{T}^{\mathrm{T}}$ has been more than two decades since the countries of central and eastern 1 Europe (CEE) underwent the dramatic economic and societal transformations associated with the transition from socialism to a market economy. Immediately following the transition ${ }^{1}$, there was an intense storm of social science research addressing the causes and consequences of a move to the market, but the storm dissipated too soon to assess long-term and enduring effects on life chances, opportunities, and other outcomes. It is only now, some 25 years later, that we are in a position to assess more fundamental long-term effects, but unfortunately most scholars have long since moved on to other questions and other countries, perhaps especially China. While important work on central and eastern Europe has continued, the pace of such research is now slower, and market transitions in countries outside of Europe have garnered the most attention in academic and public discourse.

This is problematic because short-term and long-term effects may well be quite different. It is only in the long term that we can examine and assess the full effects of the transition on the distribution of societal resources, the organization of class and economic structures, and the transmission of inequalities across generations. By contrast, the short-term outcomes are not only contaminated by the initial crisis effects of the early transitional period, but they also reflect an early and incipient form of the new economic system that may differ substantially from the mature 
form. In this article, we go beyond short-term analyses and examine the longer-term systemic effects of the transition.

We focus on the effect of the transition on the permeability of class structures as revealed in patterns of social mobility. We consider both "absolute mobility," which measures the extent to which individuals end up in different class situations from those in which they originated, and "relative mobility" (or "social fluidity"), which measures the strength of the association between class origin and destination. The centerpiece of our effort is data that allow us to compare patterns of mobility in the early 1990s and the late 2000s. These data extend into a time period well after the transition, making it possible to carry out the first long-term, cross-national assessment of the effects of the transition on class permeability. Further, and in contrast with typical single-country studies, our data cover 13 countries in central and eastern Europe, and we can therefore examine whether there are cross-national similarities in patterns of social mobility. ${ }^{2}$ Given that our primary interest is in examining the effects of marketization on social mobility, our conclusions will be significantly strengthened insofar as the same effects exist across all CEE countries that experienced the transition. The extent to which we find similarity across countries speaks to the extent to which it was the shock of marketization that led to changes in social mobility; single-country studies are susceptible to the counterclaim that changes in mobility are rather due to country-specific economic or social dynamics.

\section{Crisis Effects versus Marketization Effects}

For obvious reasons, the initial studies of social mobility published in the late 1990s and early 2000s report analyses of data drawn primarily from the 1990s, which are not well-suited for the purpose of assessing true long-term effects of the transition. Although the move away from socialism began in 1989, the period of transition extended far beyond the early 1990s, and the economic consequences reverberated throughout the whole decade. Indeed, although the changes experienced by the countries of central and eastern Europe are typically attributed to "the transition," there were in fact two transitions: the initial "crisis" transition from socialism to post-socialism and the subsequent "systemic" transition from post-socialism to a market economy. In the years following the transition from socialism, the countries of central and eastern Europe experienced a severe recession, on a similar scale to the Great Depression. The decade following the end of socialism was marked by high unemployment, a rapid shift away from manufacturing and agriculture toward the service industry, a dramatic decline in living standards and an increase in poverty rates (World Bank 2002), alongside significant increases in various indicators of social and income inequality (Milanovic 1998). As Gerber and Hout (1998) observed, the immediate posttransition period was "More Shock than Therapy," and it was only toward the turn of the century that economic growth was restored across the region and the transition recession was declared to be over (World Bank 2002:4). ${ }^{3}$

A period of flux and crisis would be expected to influence patterns of social mobility in ways quite distinct from the transition per se. During a crisis, both the processes of class attainment and of intragenerational mobility may be disrupted: 
those looking for jobs may find that their social, economic, and cultural resources offer different returns than would be expected under either socialism or a market economy, while those currently employed may be promoted, become unemployed, or be forced into underemployment. In general, we would expect a crisis to be profoundly rigidifying, largely because of its effects on unemployment and job search. As unemployment increases and jobs are scarce, competition for the remaining positions intensifies, and the average time spent on job search increases. These forces have powerful effects on an individual's reservation wage, or perhaps more pertinently, an individual's "reservation class" (i.e., the minimum socioeconomic status, hours of work, and working conditions required to induce a worker to accept a job). The effects of the crisis on one's reservation class are likely to differ by class background. The resources available to those from more advantaged class backgrounds provide a safety net that supports a long-term job search and thus a relatively high reservation class, resources that include the economic resources necessary to maintain reasonable living standards and support a family as well as the social resources available through social networks. In contrast, people from less advantaged backgrounds have much less capacity to engage in an extended and successful job search and have a relatively low reservation class. Thus, a crisis is expected to work to the relative advantage of those from higher social class backgrounds at the cost of those from lower social class backgrounds, and social fluidity is expected to decline.

Evidence from the few studies of social mobility that compare the socialist and immediate post-socialist eras is reasonably consistent with this crisis prediction. Gerber and Hout (2004) find evidence of decreasing fluidity in Russia between the end of the pretransition period and the late 1990s, reporting an increase of 26 percent in the strength of the association between origin and destination (2004:693, 696). Although they attribute this rigidification of the mobility regime to the market transition, they recognize that the mechanisms leading to the decline in fluidity are ones related to an economic crisis. For example, "A decade of economic crisis in Russia reduced the number of desirable jobs and displaced millions of workers. When the displaced workers found jobs again, these jobs mostly were in occupations closer to the workers' social origins than the ones they had before" (2004:696). If, however, different mobility mechanisms are in play in an economic crisis as compared to a market transition, then studies of mobility that focus only on crisis years are unlikely to generalize to the mobility processes observed following the transition. Recent work on Russia lends support to this claim. In a paper based on data drawn from pre- and postcrisis years, Yastrebov (2016) argues that there is little evidence for a substantial decline in social fluidity in Russia between Soviet and post-Soviet times, and that a conclusion of "no change" is well supported by his data. ${ }^{4}$

Only after the crisis instigated by the end of socialism has fully passed might we expect to observe the institutional effects of a definitive move toward a market economy, characterized as an economy in which goods, labor, and credit are allocated via prices rather than "command" and scarcity (Walder 1996:1063). It is difficult to ascertain the moment at which a transition ends and a market economy begins, but a World Bank report concluded in 2008 that, ". . . the legacy of transition is giving 
way to convergence in institutions that shape firm behavior and outcomes toward those in developed market economies" (Mitra 2008:26). Insofar as our interest is in the changes in social mobility patterns instigated by marketization, it is the period following the crisis of the 1990s that should be in focus, when the institutional changes concomitant with market reform were in place.

\section{The Implications of Marketization for Equality of Opportunity}

If the first problem with existing research on the transition is that it is focused more on crisis than transition, the second problem, perhaps surprisingly, is that a theory of the transition's effects on social structure and mobility is less well developed than might be assumed. We consider here three possible sources of a theorycounterselection narratives, market transition theory, and liberal theory-and argue that all are wanting when it comes to making sense of how the transition might play out.

The counterselection narrative emphasizes that at least some socialist societies deliberately attempted to limit the power of social background in determining occupational and class position (e.g., Szelenyi 1998; Bukodi and Goldthorpe 2010). For example, access to select educational and occupational positions was sometimes limited to children with working-class parents, a clear counterselective mechanism (e.g., Mateju 1993; although cf. Hanley and McKeever 1997). This narrative has not emerged as a full-blown theory of the transition because of various empirical problems with it. Most importantly, research on patterns of mobility under state socialism provides no strong evidence to support the view that the countries of the Soviet Union, including central European countries, were unusually open societies. Erikson and Goldthorpe's (1992) analyses of Hungary and Poland, for example, found levels of social mobility and fluidity similar to those observed in Western Europe and the United States (also Marshall, Sydorenko, and Roberts 1995; Wong and Hauser 1992; Kolosi 1988). As Gerber and Hout (2004:680) put it, "what little we know about Russian mobility in the Soviet period suggests that there was substantial intergenerational inheritance of class position," though as they also note: "the data are too sketchy to reach definitive conclusions." This conclusion can probably be taken to apply to most countries in the region before the transition.

If the counterselection narrative has proven unpersuasive, might we instead look to market transition theory as a source of theorizing about social mobility and the transition? The main problem here is that although market transition theory is clearly relevant to social fluidity, it does not treat fluidity as an explanandum in and of itself; hence, the specific implications of this theory for social mobility must be derived from more general predictions of how the move to market institutions might lead to changes in inequality (Nee 1989; Nee 1996; Nee and Matthews 1996; Cao and Nee 2000; see also Szelenyi and Kostello 1996). Nee's initial outline of market transition theory argues that the "transition to a marketlike economy should result in higher returns to human capital characteristics" (1989:674). This is sometimes 
taken to mean that marketized societies offer greater opportunities to those from disadvantaged backgrounds by providing "channels of mobility" (Heyns 2005:166).

Insofar as one focuses on rising returns to education alone, the conclusion that fluidity will increase is not at all obvious. To the contrary, if increases in the returns to education are the only changes to the existing mobility regime, this will work to strengthen, not weaken, the association between origins and destinations. If one wants to argue that fluidity is increasing with the transition, one must instead show that rising returns to education are countered by a decline in the effects of social origins on educational outcomes: if education is more tightly connected to class destinations, this change has to be counterbalanced through an educational system that allows less privileged children to benefit from education-based allocation. The liberal theory makes just such an assumption (Bell 1973; Treiman 1970), and the liberal theorists stressed that the path to industrialism is one in which increasing returns to education are accompanied by the lessening of inequalities in educational attainment. By contrast, market transition theory fails to make the case that a reduction in educational inequality would be expected to occur alongside rising returns to education upon marketization.

We could of course assume that the transition itself is unimportant and that trends in transitioning societies will be the same as the trend in other societies. If this assumption, which seems unattractive on the face of it, were indeed made, it would lead us to expect an increase in fluidity. In recent times, what might be termed a "new consensus" in empirical social mobility research has been reached: it is by now well established that in the latter decades of the twentieth century, many countries witnessed increases in social fluidity (Breen and Luijkx 2004; Breen 2004a; Breen and Jonsson 2005; Ganzeboom, Treiman, and Ultee 1991; Ganzeboom, Luijkx, and Treiman 1989; Hout 1988; Jonsson et al. 2011). Although the overall association appears to be weakening, the mechanisms through which this change is occurring are less clear (see Breen and Luijkx 2004; Breen and Jonsson 2005). To be sure, educational expansion is associated with increased social fluidity (e.g., Pfeffer and Hertel 2015), but it is rather less obvious that the relationships between origin and educational attainment as well as educational attainment and destination are changing in ways consistent with the theory.

We therefore have no established theory to call upon to generate predictions about changing patterns of social mobility resulting from transition to the market system. The liberal theory is not obviously appropriate for explaining how transitions from socialist to market economies influence social mobility. And market transition theory is mostly silent on this topic. Finally, there is little evidence supporting theories of counterselection, though such theories do at least lead to simple and firm predictions. We therefore include some of these counterselective mechanisms in the "transfer theory" we now develop.

\section{Alternative Mechanisms}

So how might we generate predictions about how mobility patterns will change with a move to the market? We propose that patterns of social fluidity will be altered by the changes in social institutions brought about by a market transition, changes that 
are distinct from those that occur in the crises following the end of socialism. The crucial changes that marketization brings about relate to the institutional structures that regulate the transfer of capital between generations. The move from socialism to the market entails the development of new "transfer institutions", with two such institutions especially prominent: institutions that regulate the transfer of physical or economic capital and institutions that regulate the transfer of human capital. The shifts in these transfer institutions with marketization are consequential for patterns of social mobility; in particular, we expect levels of social fluidity to decrease.

Marketization ushers in distinctly different institutional rules with fewer restrictions on the direct transfer of economic capital across generations; constraints on the inheritance of property and economic capital are removed, while a new emphasis on entrepreneurship encourages investment in family firms. The loosening of restrictions on the transfer of capital has implications for the level of class immobility: the direct transfer of economic capital is likely to increase the propensity for immobility for those classes in which capital investment is important, most notably for those classes in which employers and the self-employed are found.

Institutions that manage the transfer and development of human capital are also altered by marketization. The educational counterselective policies implemented by socialist countries aimed to encourage the development of human capital for those of disadvantaged class origin, thus providing opportunities for upward social mobility. By design at least, socialism was an extraordinary historical experiment in equality of opportunity (Szelenyi 1998). As new educational transfer institutions develop after the end of socialism and counterselection is abolished, we would expect a strengthening association between class origin and class destination, as the protected routes to upward mobility for children of lower class origin are taken away.

New labor market transfer institutions that develop with marketization might also lead to declines in the level of social fluidity. Although market transition theory would predict increasing returns to human capital characteristics in market economies, one of the prominent critiques of the liberal theory questions whether market economies are indeed susceptible to the functional imperatives of a move from ascription to achievement. Goldthorpe (1996) notes that in a market economy, it is employers who determine which attributes of employees are rewarded, and there are all manner of reasons why employers might privilege those with advantaged origins. A well-developed market economy thus has the potential to be less rather than more meritocratic than other types of economies and to promote less rather than more social mobility (see also Bukodi and Goldthorpe 2010; Goldthorpe and Jackson 2008; Rivera 2015). This again implies that the move from socialism to the market might have a rigidifying effect.

The increase in income inequality that would be predicted (and was observed) after the move from socialism to the market further heightens the implications of marketization for the transfer institutions that regulate the transmission of economic and human capital between generations. Increasing income disparities generate barriers to intergenerational mobility because those at the top of the class structure are increasingly advantaged relative to those at the bottom, and thus have relatively more resources to devote to processes of class reproduction. This hypothesis has 
come to increased prominence in recent years due to the takeoff in income inequality in the United States and elsewhere. Although the hypothesis has garnered most interest in the late industrial market economies of the west, the mechanisms through which income inequalities might generate reduced mobility are equally applicable to the transfer institutions of central and eastern Europe.

The data that are available to us are not numerous enough for full tests of all of these hypotheses, but we can distinguish between two types of mobility patterns that allow us to speak indirectly to the proposed mobility mechanisms associated with the development of market transfer institutions: direct inheritance (or immobility) and socioeconomic gradational mobility. Direct inheritance refers to immobility observed when individuals are found in the same class as their family of origin, indicated by clustering on the "main diagonal" of the mobility table. Once this clustering is taken into account, the residual of socioeconomic gradational mobility refers to the movement that occurs when individuals leave their class of origin. We expect to find that mobility is more likely between classes that are close together in the socioeconomic hierarchy than between classes that are further apart.

The two types of mobility processes, direct inheritance and gradational mobility, will be more or less important depending on the type of transfer institutions under consideration. Because a loosening of economic restrictions aids the transfer of economic capital across generations, direct inheritance is expected to be particularly important in describing immobility within the employer and self-employed classes. In contrast, if the decline in counterselection has decreased the propensity for upward mobility for those of disadvantaged origins, the strengthening of the origindestination association should be evident both on the main diagonal of the mobility table (because there are more "slots" available for direct inheritance for those of advantaged class origin) and off the main diagonal (because of the decline in upward mobility for those of disadvantaged class origin). Increasing income inequality will only amplify the effects of changes in transfer institutions as families will have greater economic capacity to encourage class reproduction and, where children are forced to move to other class positions, greater capacity to ensure that the children do not have to move far.

\section{Social Mobility in Comparative Context}

Our expectation then is that the new transfer institutions that developed in central and eastern Europe after the move from socialism to the market have led to a decline in social fluidity. This stands in sharp contrast to the predictions of market transition theory and the "new consensus" in more established market societies of increasing social fluidity. Predictions about social mobility in posttransition societies are of course not specific to any individual country but rather describe general processes that should obtain across societies of similar type. If general processes are at work-whereby the establishment of market institutions leads to changes in social mobility-we should be able to observe general patterns across post-socialist societies even while we see cross-country variation.

Our data are from 13 countries: Belarus, Bulgaria, Czech Republic, Estonia, Hungary, Latvia, Lithuania, Moldova, Poland, Romania, Russia, Slovakia, and 
Ukraine. Although a transition from a socialist to a market economy occurred in all of these countries, clearly the speed and the manner of the transition differed. As Walder (1996) cautions in his critique of market transition theory, "The variability of market economies warns against attempts to predict changes in inequality without first specifying the kinds of enterprises and other institutions that characterize the emerging market economy-or even the characteristics of markets themselves" (p. 1060; see Gerber 2002 for a similar discussion in the context of predictions linking marketization to stratification processes). This caution is perhaps all the more pertinent for studies of social mobility, given the lack of well-established expectations about how the move from socialism to the market would lead to changes in mobility patterns. However, while the countries included in our sample moved toward the market at different rates and in different ways, there was a clear move away from socialism in all of them. Again, if the transition from socialism to a market economy does have implications for mobility patterns, we would expect to find a strong general trend in mobility across the region.

We must here add a caveat that takes account of the particular time period to which our data relate. We have already argued that it is highly likely that a crisis of the type witnessed in the aftermath of the fall of socialism would lead to a decrease in social fluidity. Our first data point, from the early 1990s, captures mobility patterns that in large part represent the situation that prevailed under socialism but that will also to some extent reflect the immediate crisis. In comparing our early and late time periods, therefore, it is possible that the earlier time point represents a worse situation than that which prevailed under socialism and, in consequence, that the level of social fluidity is artificially depressed relative to socialist levels. It is important that the structure of our analysis biases against finding the decrease in fluidity that our "transfer theory" implies.

In the rest of this article, we examine patterns of change in social mobility in our 13 central and eastern European countries. Our focus is on social fluidity, or relative social mobility, but we begin our analyses with a discussion of the absolute rates of people experiencing social mobility. Our main concern is whether there are general patterns across the whole of the region, but we also test for individual country differences. In the following section, we describe our unique data source and the measures used in the analyses.

\section{Data and Measures}

Our data are drawn from sample surveys of the electorates in each country collected under the auspices of the EUREQUAL project ${ }^{5}$, a European Union-funded research program. Data collection was undertaken by local agencies within each country on a stratified random probability sample of the electorate. Identical questionnaires were administered to respondents in each country, having been translated by local agencies. Table 1 summarizes the data. For most countries, the data come from two surveys, one conducted in the early 1990s and one conducted in the late 2000s, but there are four countries in which more than one survey was conducted for each period. Sample sizes for most countries are respectable, but not plentiful, 
Table 1: Data information for each country.

\begin{tabular}{lrrrr}
\hline \multirow{2}{*}{ Country } & \multicolumn{2}{c}{ Year(s) data collected } & \multicolumn{2}{c}{ N } \\
\hline Belarus & Early 1990s & Late 2000s & Male & Female \\
Bulgaria & 1993 & 2007 & 667 & 808 \\
Czech Republic & 1993 & 2007 & 663 & 834 \\
Estonia & 1994 & 2007 & 801 & 866 \\
Hungary & 1993,1995 & 2007 & 1,422 & 1,536 \\
Latvia & 1993 & 2007 & 675 & 820 \\
Lithuania & 1996 & 2007 & 951 & 1,028 \\
Moldova & 1993,1997 & 2007 & 1,398 & 1,511 \\
Poland & 1996 & 2007 & 753 & 1,078 \\
Romania & 1993 & 2007 & 1,072 & 1,133 \\
Russia & 1993 & 2007 & 958 & 868 \\
Slovakia & $1993,1995,1996$ & 2007 & 2,274 & 2,793 \\
Ukraine & 1994 & 2007 & 811 & 935 \\
& $1993,1995,1998$ & 2007 & 2,460 & 3,505 \\
Total & & & & 17,715 \\
\hline
\end{tabular}

after taking missing data into account. This in turn places some limits on variable construction and analysis.

Mobility tables are constructed using information provided by the respondent about their own and their parents' occupations and employment status, subsequently coded by the data providers into EGP classes (Erikson, Goldthorpe, and Portocarero 1979; Erikson and Goldthorpe 1992; for details of the data coding, see Loveless 2009). In order to ensure sufficient statistical power for the analyses, we use a six-class version of the schema, as follows:

I. Higher managerial and professional

II. Lower managerial and professional

III. Routine nonmanual

IV. Self-employed (including self-employed farmers)

V. Manual supervisors and skilled manual

VI. Semi- and unskilled manual (including farm laborers)

Class origin is measured as the class position of the household when the respondent was aged 14, operationalized as the class position of the father; where father's class is missing, we use mother's class. ${ }^{6}$ Class destination is measured as the respondent's own class at the time when the survey was conducted. We restrict our sample to respondents aged between 25 and 69 .

Our use of the EGP schema to operationalize class position follows the practice of most previous research in the region (e.g., Erikson and Goldthorpe 1992; Gerber 
and Hout 2004; Róbert and Bukodi 2004; Mach 2004), and ensures comparability with previous mobility studies beyond the countries in our sample. There have inevitably been debates about the applicability of standard social class measures in central and eastern Europe. In these debates, some of the early commentators argued that class inequalities in central and eastern Europe were less prominent (e.g., Ossowski 1963; Wesolowski [1966] 1977), others proposed class schemes that took into account the putatively special features of class systems in central and eastern Europe (e.g., Parkin 1971; Lipset and Dobson 1973; Konrad and Szelenyi 1979; Strmiska 1987; Kolosi 1988), and yet others asserted that processes of industrialization and modernization produced occupational and status structures similar to those in established market economies (Kerr 1983; Hoffman and Laird 1982). The latter position has considerable evidence behind it. Studies examining the appropriateness of the use of the EGP schema in the region at the very start of the post-socialist era reveal patterns of association between class position and relevant indicators of employment conditions, rewards, and political and social identities that are reassuringly similar to those found in the west (Evans 1997; Evans and Mills 1999; Evans 2006). ${ }^{7}$

\section{Absolute Mobility}

We begin by considering the extent to which those living in central and eastern Europe experienced intergenerational social mobility between the early 1990s and the late 2000s. Absolute mobility rates are presented in Figure 1 for each of the 13 countries separately and for the whole of the region; separate bars indicate the proportion of those in each country experiencing any mobility ("total" mobility rate) and those experiencing upward, downward, or horizontal mobility. By convention, mobility is defined in relation to a three-class ordered grouping of our EGP classes: (1) classes I and II, (2) classes III, IV, and V, and (3) class VI (see Breen 2004a:18). Upward and downward mobility entails movement among the ordered groups, while horizontal movement entails movement within a group. Total mobility is the sum of upward, downward, and horizontal mobility.

If we focus first on total rates of mobility and immobility across the whole of the region, we see some small changes between the early 1990s and the late 2000s. The number of men experiencing intergenerational social mobility declined slightly over the periods, from 67 percent in the early 1990s to 66 percent in the late 2000s $(p=0.08)$, and there is a corresponding increase in the percentage of men who remain intergenerationally immobile from 33 percent to 34 percent. In both periods, women are significantly more likely to be mobile than men, a finding that would be expected on the basis of previous mobility research (e.g., Erikson and Goldthorpe 1992:244; Breen and Luijkx 2004:65), with around 73 percent experiencing mobility from their class of origin in both the 1990s and the late 2000s. These total mobility rates are the overall result of changes in the levels of upward, downward, and horizontal mobility. Most notably, rates of upward mobility have declined (from 38 percent to 36 percent for men and from 44 percent to 43 percent for women), as have rates of downward mobility (from 21 percent to 19 percent for men and from 17 percent to 15 percent for women). Alongside these trends, there has been 


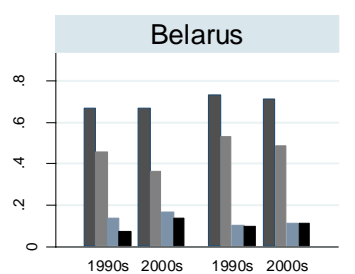

$\mathrm{M}$

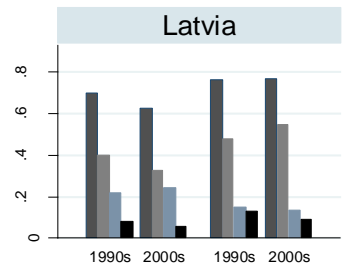

$\mathrm{M}$

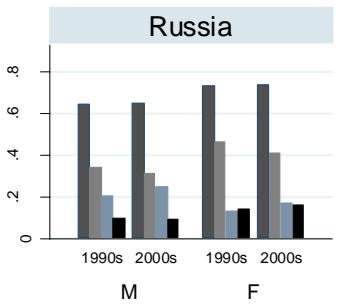

Bulgaria

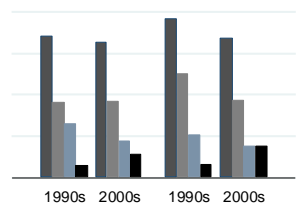

$\mathrm{M}$

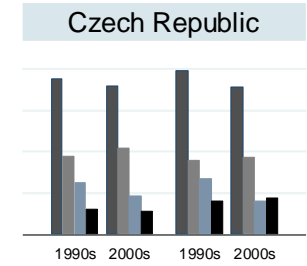

$\mathrm{M}$
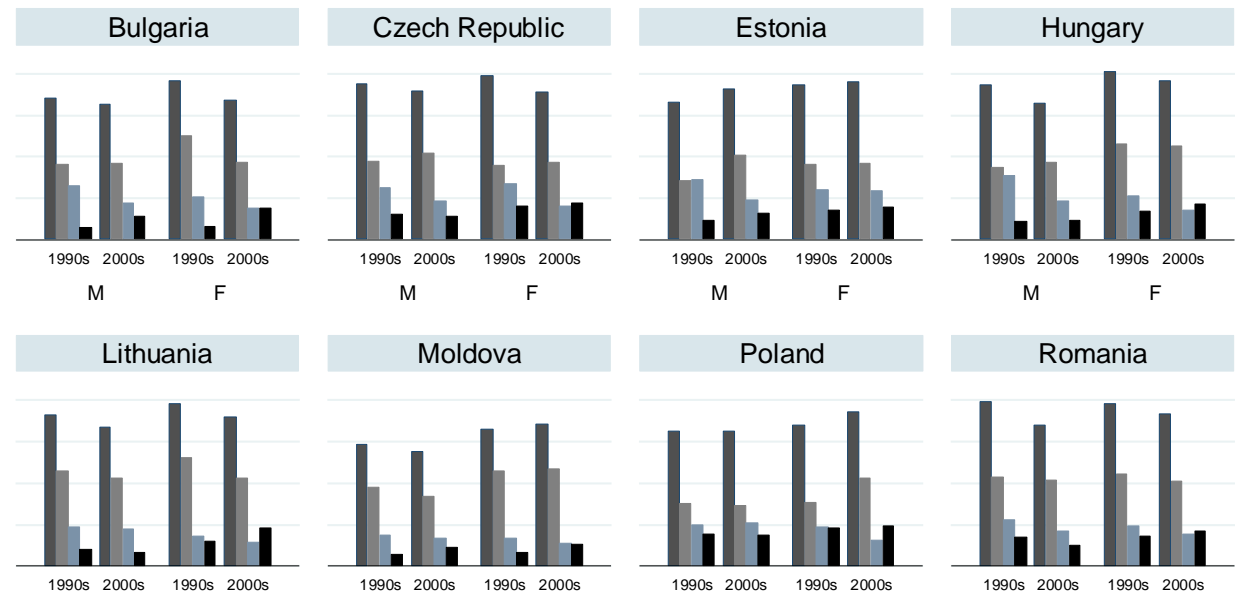

M

Ukraine

Slovakia
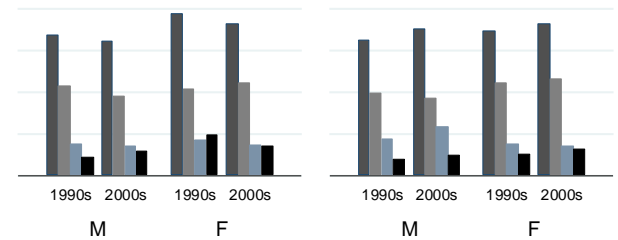

$\mathrm{M}$

$\mathrm{F}$

Total
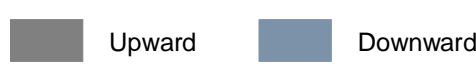

Downward

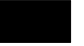

Horizontal

Figure 1: Proportion of men and women in the early 1990s and late 2000s experiencing mobility ("total mobility rate"), upward mobility, downward mobility, and horizontal mobility in each of the 13 countries and in total across the region.

a significant increase in rates of horizontal mobility for both men and women, although the increase is quite small. In general, across central and eastern Europe, marketization ushered in only small changes to patterns of absolute social mobility, but where changes are found, they tend to be in the direction of less mobility.

Turning to the mobility patterns for individual countries, we see no evidence of systematic deviations from this general pattern. Although the decline in total mobility is more marked in some countries (e.g., Czech Republic and Hungary) than in others, there is no clear relationship between total mobility patterns and marketization, just as there is no consistency across similar countries in the extent to which changes in total mobility are generated by changes in upward, horizontal, or downward mobility.

\section{Relative Mobility}

We turn now to consider relative rates of mobility. Relative rates are commonly understood to provide a good measure of equality of opportunity for those of different class backgrounds (although the extent to which these rates capture the 
concept of equality of opportunity has been questioned—see Swift 2004; Breen 2010). Although trends in absolute mobility are an important backdrop to the structural changes that marketization wrought, the transfer account we have developed speaks to the patterns of advantage that a privileged birth brings relative to a nonprivileged birth.

We fit association models to describe how origin and destination are related across time and across countries. ${ }^{8}$ We use three (related) types of models in the analysis to fully explore the patterns of association, all of which are well-established in the literature on social mobility. The association models that we deploy may be understood as the sociological counterparts to the intergenerational elasticities that economists commonly employ in studies of income mobility. The results of all models are presented in Table 2, to which we will refer throughout this section. For each model, we show the likelihood ratio statistic $\left(\mathrm{G}^{2}\right)$, the degrees of freedom, the "Bayesian Information Criterion" (BIC) statistic, and the index of dissimilarity. We use these statistics to determine the goodness of fit of the models and will later present coefficients from our preferred models to further elucidate the patterns that we find. The standard baseline model, against which we can test improvements in model fit, is known as the "conditional independence" model:

$$
\log F_{i j k}=\mu+\lambda_{i}^{O}+\lambda_{j}^{D}+\lambda_{k}^{T}+\lambda_{i k}^{O T}+\lambda_{j k}^{D T}
$$

where $F_{i j k}$ is the expected frequency in cell $i j k$ of the three-way table comprising class of origin $(\mathrm{O})$, class of destination $(\mathrm{D})$, and time $(\mathrm{T})$. On the right-hand side of the equation, $\mu$ is a scale factor, while $\lambda_{i}^{O}, \lambda_{j}^{D}$, and $\lambda_{k}^{T}$ represent the main effects of the distribution of individuals over origins, destinations, and time periods, respectively. The remaining terms posit an association between origins and time and between destinations and time. In our first model in Table 2, we fit the conditional independence model, which in our case includes additional terms to account for differences by sex and country in the origin and destination distributions. The model inevitably fits poorly and serves only as a basis for comparison.

Does social fluidity change over time? Our primary research question can be initially addressed by comparing models 2 and 3. Model 2 extends the conditional independence model by fitting an additional term to account for the association between origin and destination (the "constant social fluidity" model), while model 3 tests whether that association changes over time. A comparison of the two models shows that model 3 is a significant improvement over model 2, meaning that we can detect over-time changes in fluidity between the early 1990s and late 2000s. ${ }^{9}$

To test for the nature of the changes over time, we fit model 4, the "Unidiff" (Erikson and Goldthorpe 1992), also known as the log-multiplicative layer effect model (Xie 1992). This model posits that all of the odds ratios within the mobility table change in a uniform fashion between the two time periods and is of the form:

$$
\log F_{i j k}=\mu+\lambda_{i}^{O}+\lambda_{j}^{D}+\lambda_{k}^{T}+\lambda_{i k}^{O T}+\lambda_{j k}^{D T}+\beta_{k} X_{i j}
$$

where the $X_{i j}$ term represents the pattern of association between origin and destination class, and the $\beta_{k}$ term measures the relative strength of association that is specific to a time period. This model offers a significant improvement in fit, and 
Table 2: Model fit statistics for the log-linear and log-multiplicative models.

\begin{tabular}{|c|c|c|c|c|}
\hline Model & $\mathrm{G}^{2}$ & d.f. & BIC & $\Delta$ \\
\hline $\begin{array}{l}\text { 1. Conditional independence } \\
\mathrm{O}^{*} \mathrm{C}^{*} \mathrm{~S}^{*} \mathrm{~T}+\mathrm{D}^{*} \mathrm{C}^{*} \mathrm{~S}^{*} \mathrm{~T}\end{array}$ & $3,825.5$ & 1,300 & $-9,686$ & 12.0 \\
\hline $\begin{array}{l}\text { 2. Constant social fluidity } \\
O^{*} C^{*} S^{*} T+D^{*} C^{*} S^{*} T+O^{*} D\end{array}$ & $1,890.1$ & 1,275 & $-11,361$ & 7.5 \\
\hline $\begin{array}{l}\text { 3. Social fluidity varies by time } \\
\mathrm{O}^{*} \mathrm{C}^{*} \mathrm{~S}^{*} \mathrm{~T}+\mathrm{D}^{*} \mathrm{C}^{*} \mathrm{~S}^{*} \mathrm{~T}+\mathrm{O}^{*} \mathrm{D}^{*} \mathrm{~T}\end{array}$ & $1,806.8$ & 1,250 & $-11,185$ & 7.3 \\
\hline $\begin{array}{l}\text { 4. Unidiff } \\
\mathrm{O}^{*} \mathrm{C}^{*} \mathrm{~S}^{*} \mathrm{~T}+\mathrm{D}^{*} \mathrm{C}^{*} \mathrm{~S}^{*} \mathrm{~T}+\text { Unidiff }\left(\mathrm{O}^{*} \mathrm{D} \text { over } \mathrm{T}\right)\end{array}$ & $1,848.6$ & 1,274 & $-11,392$ & 7.5 \\
\hline $\begin{array}{l}\text { 5. Social fluidity varies by country } \\
O^{*} C^{*} S^{*} T+D^{*} C^{*} S^{*} T+O^{*} D^{*} C\end{array}$ & $1,297.7$ & 975 & $-8,836$ & 5.6 \\
\hline $\begin{array}{l}\text { 6. Unidiff while allowing for variation by sex and by } \\
\text { country } \\
O^{*} C^{*} S^{*} T+D^{*} C^{*} S^{*} T+O^{*} D^{*} S+O^{*} D^{*} C+ \\
\text { Unidiff }\left(O^{*} D \text { over } T\right)\end{array}$ & $1,235.1$ & 949 & $-8,628$ & 5.5 \\
\hline $\begin{array}{l}\text { 7. Uniform inheritance and gradational scale vary by } \\
\text { time, sex, and country } \\
\mathrm{O}^{*} \mathrm{C}^{*} \mathrm{~S}^{*} \mathrm{~T}+\mathrm{D}^{*} \mathrm{C}^{*} \mathrm{~S}^{*} \mathrm{~T}+\mathrm{I}+\mathrm{U} I^{*} \mathrm{~T}+\mathrm{UI} I^{*} \mathrm{~S}+\mathrm{UI}^{*} \mathrm{C}+\mathrm{GS}+ \\
G S^{*} \mathrm{~T}+\mathrm{GS} S^{*}+\mathrm{GS}^{*} \mathrm{C}\end{array}$ & $1,749.9$ & 1,265 & $-11,398$ & 7.1 \\
\hline $\begin{array}{l}\text { 8. Uniform inheritance and gradational scale vary } \\
\text { interactively by time, sex, and country } \\
O^{*} C^{*} S^{*} T+D^{*} C^{*} S^{*} T+I+U I^{*} S^{*} T+U I^{*} C^{*} T+G S+ \\
G S^{*} S^{*} T+G S^{*} C^{*} T\end{array}$ & $1,563.6$ & 1,239 & $-11,314$ & 6.5 \\
\hline
\end{tabular}

Note: O: origin; D: destination; C: country; S: sex; T: time; UI: uniform inheritance; I: inheritance; GS: gradational scale

the Unidiff parameter of 1.37 provides an indication that the odds ratios describing the relationship between origin and destination are, on average, larger in the later period than in the earlier period. This stands as evidence in favor of the hypothesis of declining social fluidity.

To ensure the finding of declining fluidity is stable across all of the countries in $\mathrm{CEE}$, rather than being a feature of just a handful of countries, we complete our initial analyses by testing for variation across countries. In model 5 , we fit a term to test whether the origin by destination association differs in strength across the countries; the model is an extension of the constant social fluidity model (model 2 ), such that differences in the level of fluidity across countries are accounted for 
but differences over time are not. The model fits poorly but is an improvement in fit over the constant social fluidity model $\left(\mathrm{G}^{2}\right.$ is reduced by 592.4 for 300 d.f., $p<$ 0.01 ), a result that suggests that there is variation across countries in the overall level of social fluidity. In model 6, we extend model 4 to test whether changes over time are still evident after allowing for the country variation. We further allow the origin-destination association to differ by sex, thus ensuring that any changes found over time will be uncontaminated by the three-way association among these variables. In this elaborated version of the Unidiff model, which fits significantly better, the Unidiff parameter remains positive, with a value of 1.32 .

We carry out two further robustness checks. First, we address a concern in the literature that a finding of decreased fluidity between two periods could be driven by a methodological artifact, namely, "the confounding influence of the uniqueness of farmers" (Xie and Killewald 2013:2018). If the proportion of the labor force engaged in agriculture changed substantially between our two periods-and marketization clearly did have consequences for the proportion of the labor force engaged in agriculture across central and eastern Europe-we may see an overall decline in fluidity as a result. To test for this possibility, we exclude farmers from the analysis, but the finding of decreased fluidity is sustained. ${ }^{10}$ Second, we assess to what extent the decline in fluidity can be attributed to a period change-as arguments linking changes in fluidity to marketization would imply-rather than to cohort replacement. If it were the case, for example, that those in the labor market in both the early 1990s and late 2000s had very similar levels of social mobility, and the decline in fluidity was attributable to older cohorts with relatively high levels of mobility being replaced by younger cohorts with lower levels, it might lead us to question whether or not marketization did in fact act as a general shock to social reproduction. We unfortunately have too few cases to carry out a full cohort analysis while taking into account variation across countries, but we carry out two tests that cast light on the processes at work.

First, we compare fluidity across the two time periods for only those people who could have been present in the labor force in both periods of time. When excluding from the sample those individuals who would have "aged in" or "aged out" by the second time period, the Unidiff coefficient capturing change over time is estimated at 1.37. Second, we directly compare two sets of cohorts: the "aged in" cohort from the second time period is compared with a similar-aged cohort in the first time period, and the "aged out" cohort present in the first time period but not the second is compared with a similar-aged cohort in the second period. ${ }^{11}$ When we compare changes over time for each of these sets of cohorts, we see that although decreases in fluidity are observed for both comparisons, the decrease is stronger for the "aged out" comparison than for the "aged in" comparison (Unidiff $=1.45$ for the "aged out" comparison, 1.16 for the "aged in" comparison), a finding that is unsurprising given that the "aged in" group is too young to have achieved occupational maturity. The results of our cohort-based analyses are consistent with the claim that a powerful mobility-reducing period effect is in play. 


\section{Exploring the Shape of Fluidity}

The foregoing models have demonstrated that social fluidity, captured in the association between social origin and social destination, has declined over the time period that we are considering. We now move on to establish the nature of the changing associations between origin and destination by employing models that allow us to identify specific features of the mobility table that might not be well captured in our previous models; most importantly, these models allow us to isolate the "main diagonal" association in the table from other associations. As we described in the introduction, different mechanisms are likely to be responsible for changes in the two types of association, and we therefore have an interest in distinguishing between diagonal and off-diagonal mobility. In additional Unidiff models (not shown), we tested for changes in the associations on the main diagonal and changes in the off-diagonal associations, which allowed us to ask whether the tightening relationship between origin and destination is characteristic of the whole mobility table or just of particular associations. The Unidiff parameters indicated strengthening in both the diagonal and off-diagonal associations between the two time periods, confirming that both types of association are of interest and that both must be parameterized appropriately.

We therefore fit first a "uniform inheritance" effect to capture inheritance on the main diagonal (e.g., Grusky and Hauser 1984; also known as "semi-quasi-perfect mobility," see Breen 2004a:26). This effect posits that there is "stickiness" on the main diagonal, such that children born into one class are likely to end up in that same class, but posits perfect mobility elsewhere in the table, such that if children move from their origin class, they are no more likely to end up in one class than another. As this off-diagonal "perfect mobility" assumption is unlikely to be a true reflection of the mobility processes at work, we fit a second effect, which we label a "socioeconomic gradational" effect. This effect allows us to test whether intergenerational mobility is more likely between classes that have a similar socioeconomic standing than between classes that have a very different socioeconomic standing (e.g., Hout 1988; Jonsson et al. 2009). ${ }^{12}$ Our modeling strategy allows us, therefore, to separately identify immobility on the main diagonal and mobility off the main diagonal, which is constrained to be determined by the socioeconomic distance between classes (see also Ganzeboom et al. 1989).

Model 7 includes the terms that test for uniform inheritance and socioeconomic (gradational) affinities among classes. As we have already established that the level of fluidity changes between the two time periods, we allow the strength of the uniform inheritance and socioeconomic gradient parameters to vary over time. We also allow the strength of these parameters to vary over countries and to vary between men and women. Importantly, at this stage we do not allow the strength of the parameters to vary across time and countries simultaneously; that is, we do not fit the three-way interactions between the mobility terms, time, and country.

The changes over time in the level of fluidity are confirmed in model 7, with both the uniform inheritance by time and socioeconomic gradient by time parameters indicating declining fluidity between the two time periods. The uniform inheritance parameter indicates that there is a statistically significant 9 percent increase between 
the two periods in the chances of a child inheriting the same class position as their parents rather than moving to another class $\left(\mathrm{e}^{0.09}=1.09, p<0.05\right)$. The strengthening association between origin and destination is also reflected in the socioeconomic gradient parameter, which is both positive and significant. On average, in our sample of countries, the coefficient for the socioeconomic gradient term increases by around 36 percent between the two periods.

The move to marketization, therefore, witnessed a decline in fluidity throughout the mobility table. Across central and eastern Europe, the chances of immobility increased while the chances of off-diagonal socioeconomic mobility decreased. As stated above, in our current model we allow for differences across countries in the base level of fluidity by including interactions between country and the uniform inheritance and socioeconomic gradient parameters. In this model, we also allow for differences in the level of fluidity by sex, although the results show that the two mobility parameters for men and women are not in fact significantly different. Again, we do not in this model allow for the three-way interactions between country, the two mobility variables, and time; in other words, we assume that countries differ in their mobility regimes in the earlier period, but that these regimes become no more or less different in the later period. In Figure 2, we present the country differences in the uniform inheritance and socioeconomic gradient parameters as they stand in the earlier period; significant differences from Russia, the reference category in the analysis, are highlighted. The socioeconomic gradient parameters have been multiplied by 100 for ease of presentation. ${ }^{13}$

The figure demonstrates that there are substantial differences among countries in their base level of social fluidity, as captured in the uniform inheritance and socioeconomic gradient parameters. Russia appears to be one of the more immobile countries in the region; in seven countries we see a significantly higher level of fluidity as captured in either the uniform inheritance or the socioeconomic gradient parameter. Estonia and Hungary are found to have particularly low levels of uniform inheritance, indicating that in these countries there is a lower propensity for individuals to inherit the class position of their parents than in the rest of the region. In Estonia, this low level of uniform inheritance is offset by a significantly higher level of off-diagonal association, as reflected in the socioeconomic gradient parameter. Which countries have, by contrast, lower levels of fluidity? The figure shows that both Moldova and Poland have substantially higher levels of uniform inheritance than other countries in CEE. This high level of uniform inheritance is likely to be attributable to the role played by the large agricultural sector, as the intergenerational transfer of land by peasant landowners is a notable feature of the Moldovan and Polish class structures.

An important extension to model 7 is to test whether the differences over time in the pattern of social fluidity are the same across all countries (or equivalently, whether the differences across countries are the same in the two time periods). We argued earlier that marketization was a shock that hit all countries in central and eastern Europe and that the establishment of new market transfer institutions would be expected to lead to decreased fluidity in all countries alike. We therefore introduce three-way interactions among the fluidity parameters, time, and country; model fit statistics are included in Table 2 (model 8). Of most interest are the 


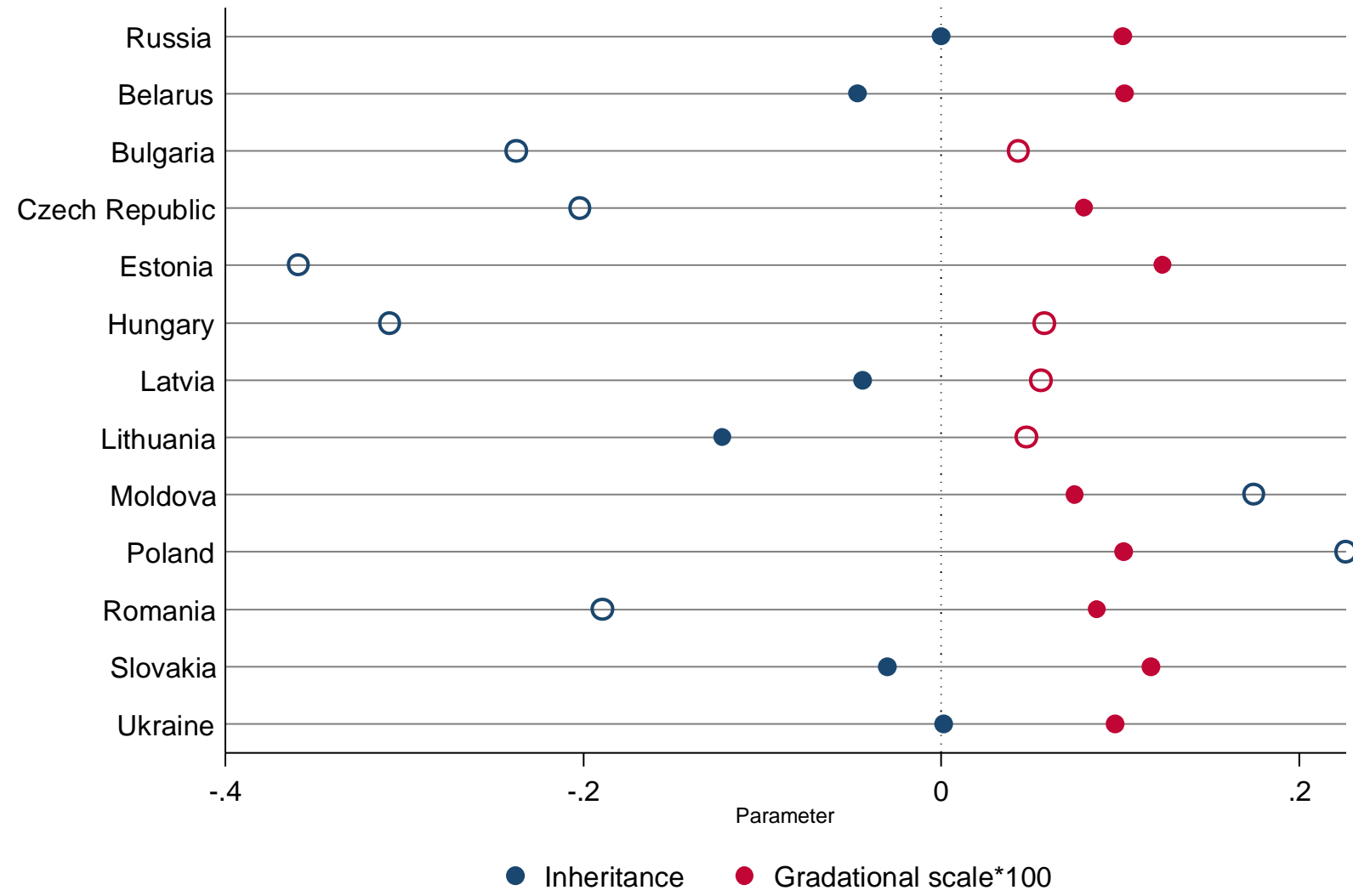

Figure 2: Parameters from model 7 for uniform inheritance and gradational mobility for each country (Russia takes the values of the UI and GS terms, UI here set to 0; other countries then plotted using $\mathrm{UI}^{*} \mathrm{C}$ and GS* terms). Hollow circles indicate significant differences from reference category of Russia $(p<0.05)$.

parameters for the three-way interactions, plotted in Figure 3, which show the magnitude of the change over time in uniform inheritance and socioeconomic gradational mobility for each country. Russia is again the base category against which significance is assessed, and parameter differences are shown relative to the early 1990s time period.

When we allow the mobility by time parameters to differ by country, we see considerable support for our broad conclusions. Of the 26 coefficients graphed in Figure 3,17 are positive and only 9 are negative. In every country but Ukraine, at least one of the mobility parameters shows declining fluidity over time. The most unambiguous declines in fluidity are observed for Bulgaria, the Czech Republic, Hungary, Lithuania, and Romania.

Even if we see evidence of declining fluidity in almost every country, it is clear that there is substantial cross-national variation as well. In some cases, such as Slovakia, an increase in one of the parameters is offset by a decrease in the other mobility parameter. In Russia, Belarus, and Ukraine, fluidity appears to be relatively stable over time. 


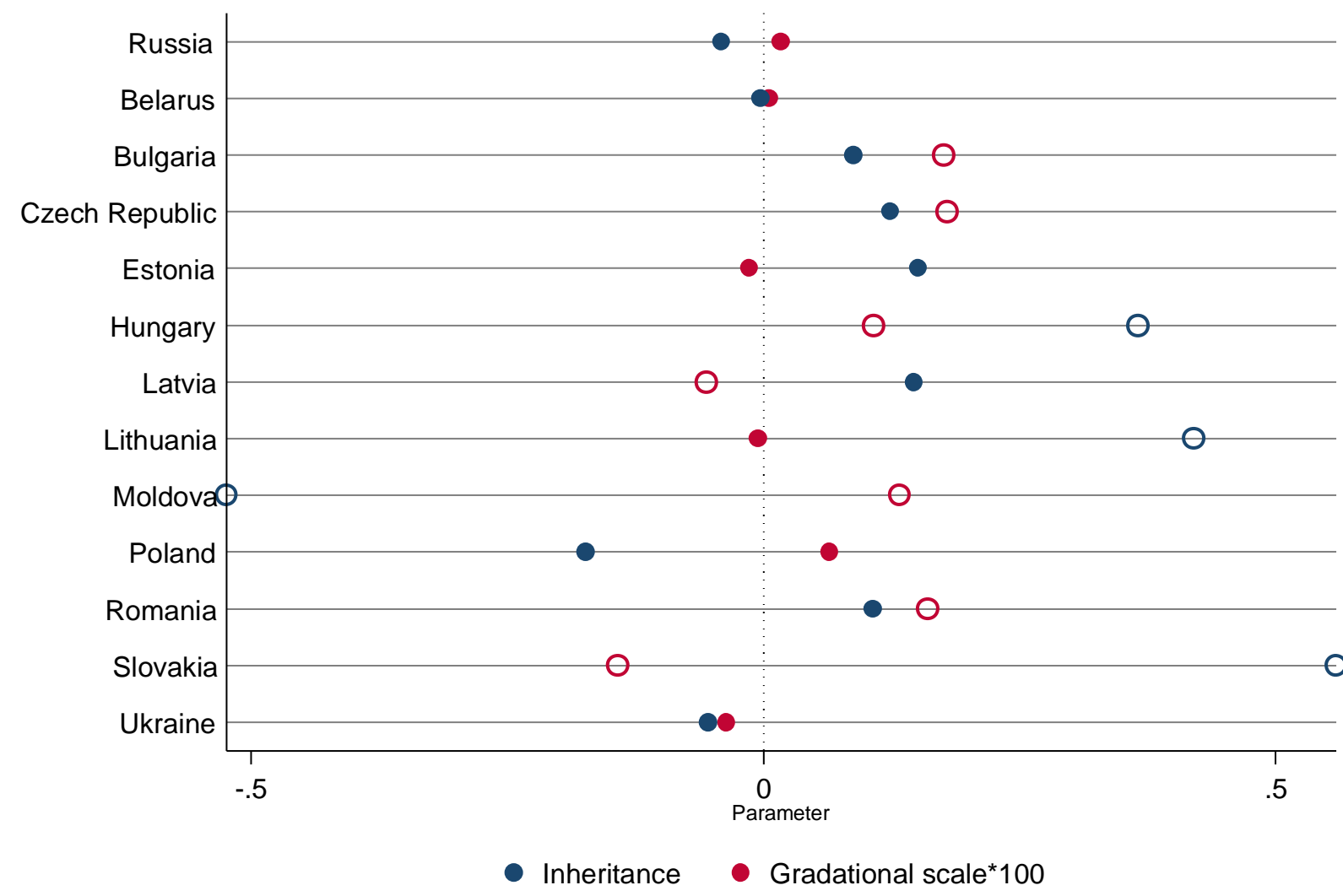

Figure 3: Parameters from model 8 for the differences over time in uniform inheritance and gradational mobility (Russia takes the values of the $\mathrm{UI}^{*} \mathrm{~T}$ and $\mathrm{GS}{ }^{*} \mathrm{~T}$ terms; other countries then plotted using $\mathrm{UI}^{*} \mathrm{~T}^{*} \mathrm{C}$ and $\mathrm{GS}^{*} \mathrm{~T}^{*} \mathrm{C}$ terms). Hollow circles indicate significant differences from reference category of Russia $(p<0.05)$.

In determining whether model 7 or model 8 is a more reasonable description of the data, we can compare the fit statistics for the models and ask which is preferred according to standard statistical criteria. On the basis of the model fit statistics, we see that although the fit is significantly improved by moving from model 7 to model 8 ( $\mathrm{G}^{2}$ reduced by 186.3 for 26 d.f., $\left.p<0.01\right)$, the latter model is still a poor fit to the data $(p<0.01)$, and the BIC statistic favors model 7. It is not unusual for the BIC statistic to favor a more parsimonious but substantively less revealing model (Raftery1995; Weeden and Grusky 2005). A reasonable way forward in such circumstances is to be guided by substantive concerns, and in this case, we must therefore consider whether the cross-national differences observed in model 8 have a sensible substantive interpretation.

We have considered a range of possible explanations for the cross-national patterns in the changes in mobility parameters. An obvious factor to consider is the extent to which each of these countries has embraced marketization-as we emphasized earlier, although every country moved away from socialism, they embraced market institutions to differing degrees. The concept of marketization is difficult to measure convincingly, but the World Bank report Unleashing Pros- 
perity includes a figure summarizing "productivity and progress in reform in the region" (2008:6, Figure 2b), in which the central and eastern European countries are ranked according to their total factor productivity growth and score on the EBRD transition index. ${ }^{14}$ For neither of the mobility parameters in Figure 3 do we find significant relationships with scores on the transition index: the uniform inheritance parameters $\left(\mathrm{UI}^{*} \mathrm{~T}^{*} \mathrm{C}\right)$ are moderately positively correlated with changes in marketization scores between the two time periods $(r=0.46, p=0.12)$, but we do not see the same relationship between the gradational scale parameters $\left(\mathrm{GS}^{*} \mathrm{~T}^{*} \mathrm{C}\right)$ and changes in marketization scores $(r=0.10, p=0.74)$. It is perhaps not surprising that we observe a stronger relationship with changes in marketization scores for the uniform inheritance parameters than for the gradational scale parameters, given that the marketization scores are largely based on characteristics of the economy and infrastructure and do not capture changes in all of the transfer institutions that we identified as being of interest in the introduction. In particular, changes in the transfer institutions that we predicted would be reflected in gradational mobility are not well captured in the EBRD measures.

Scatterplots of the mobility parameters against marketization scores are included in the online supplement. Attempts to explain the mobility parameter patterns using alternative country-level measures-such as GDP, economic growth, and income inequality—were less fruitful. ${ }^{15}$ Given that we do not have strong statistical or substantive grounds for preferring the complications of model 8 over the more parsimonious model 7, the most secure conclusion is to emphasize the common tendency of a substantial decline in fluidity across the countries of central and eastern Europe between the early 1990s and the late 2000s.

\section{Discussion and Conclusions}

Studies of social class mobility in established market societies have reached a consensus that recent decades have witnessed a decline in the association between origin and destination. Where exceptions to this new consensus pattern are found, the evidence is in favor of stability over time, not decreasing fluidity. Even in the United States, where a recent resurgence of mobility research has been focused on the search for evidence of decreasing mobility in a highly unequal society, an overall secular decline in fluidity is yet to be detected (Chetty et al. 2014; although see also Mitnik, Cumberworth, and Grusky 2016)

The results presented here reveal that-when attention turns to marketizing countries - there is indeed a strong secular trend toward declining fluidity. Although countries with established market economies may be experiencing increasing fluidity, evidence of declining fluidity is to be found in the nascent market societies of central and eastern Europe. For these countries, the path to the market was paved not with increased equality of opportunity but rather with a tightening of the socioeconomic bonds between generations. This decline in social fluidity appears to be a feature of marketization per se, although to the extent that we find differences in fluidity patterns across countries, it does appear that the countries that marketized most rapidly and most decisively are also those with the largest declines in fluidity. Our results are therefore strongly at odds with the predictions 
from market transition theory, at least insofar as that theory is taken to imply, as it typically is, that increasingly meritocratic selection will bring about increased social fluidity.

Social mobility has typically been marked by relatively slowly evolving patterns (Breen 2004b; Ganzeboom et al. 1989) or even stasis (Erikson and Goldthorpe 1992). We find, in contrast, a dramatic change over the relatively short time period examined here. Our estimates suggest a 30 to 40 percent increase in the size of the odds ratios characterizing the mobility table between the start of the post-socialist period and the late 2000s, when the crisis of the 1990s had passed and more stable socioeconomic market systems and transfer institutions had been established.

We further argued that it is critical to separate out the effects of a crisis from the effects of marketization, and that the single-country studies (e.g., Hungary, Poland, and Russia) that have been published to this point have failed to capture true market transition effects. Our later data point allows us to test whether the mobility regimes of the mature posttransition societies are different in character from the mobility regimes of the immature, crisis-ridden societies of the 1990s. Even if we ultimately favored a model that does not posit differences across countries, when we did allow for these differences, we found evidence of declining fluidity for both Hungary and Poland in our analysis but relative stability for Russia. Russia's slower rate of marketization might account for this finding. It is also possible, however, that Gerber and Hout's (2004) finding of a decline in fluidity captures the true transition effect, not just a crisis effect, and we capture only what has occurred since that point. We cannot test this possibility directly, but we note that our results for Russia are consistent with Yastrebov's recent (2016) claim-based on a cohort analysis of retrospective data collected between 1994 and 2013 - that social fluidity in Russia was essentially stable between the pretransition and posttransition eras.

We acknowledge that for almost all of our 13 countries, the sample size is smaller than ideal, and that therefore our study is not well suited to examine country-level patterns of fluidity nor to test for the individual-level mechanisms driving mobility patterns. The sample is adequate, however, for detecting the overall trend, at least when that trend is a strong one. We did indeed find in this case a strong 30 to 40 percent decline in fluidity. It is entirely possible that further declines will be observed as marketization continues to unfold. Moreover, because the countries in our study were hit hard by the Great Recession (with some relatively slow to recover), it is not implausible that many central and east European countries are even more rigid now than they were at the end of the study. Continuing economic instability in parts of central and eastern Europe layered on top of the transition from a command to a market economy suggests a dark future for the post-socialist world of mobility.

\section{Notes}

1 We use the term "transition" to refer to the changes associated with the move from socialism to the market. We recognise that some scholars reject the use of this term because it can be taken to imply a common trajectory and common destination shared by all societies undergoing a market transition (Heyns 2005:164). 
2 Our data are from Belarus, Bulgaria, Czech Republic, Estonia, Hungary, Latvia, Lithuania, Moldova, Poland, Romania, Russia, Slovakia, and Ukraine. We refer to these countries as constituting "central and eastern Europe" so that we may discuss the entire region covered efficiently. It should be noted, however, that the former socialist states of central and eastern Europe are often classified as either "CEE" or "CIS" countries, with countries to the west of the former Soviet Union plus the Baltic States falling into the CEE category, and former Soviet Republics falling into the CIS category. Our sample therefore represents both CEE and CIS countries, and by referring to "central and eastern Europe" we mean only to identify a broad geographic area rather than a specific geopolitical entity.

3 There is variation across the countries of central and eastern Europe in the extent to which the recession hit. The World Bank (2002:3) finds distinct differences in growth rates across countries, particularly when comparing the CIS with central and southeastern Europe and the Baltics. (World Bank 2002:3). The CIS was hit by a particularly long and deep recession, while the latter areas recovered more quickly from the economic crisis.

4 Róbert and Bukodi (2004) also conclude that there was no change in social fluidity between the Soviet and post-Soviet period: they find an insignificant decrease in fluidity for men in Hungary but stability for women; cf. Mach (2004) on Poland, who found an increase in social fluidity for men in the 1990s but stability for women.

5 "EUREQUAL" is the user-friendly version of the full project title: "Social Inequality and Why it Matters for the Economic and Democratic Development of Europe and its Citizens: Post-Communist Central and Eastern Europe in Comparative Perspective" (Whitefield and Evans 2007). Data from 2007 were pooled with data collected in the 1990s as part of the United Kingdom ESRC-funded project "Emerging Forms of Political Representation and Participation in Eastern Europe" (Evans et al. 1993). For further information on the combined dataset and codebook for both waves, see Loveless (2009) or http:/ / eurequal.politics.ox.ac.uk/.

6 We have tested different operationalizations of social class origin, including a measure of "dominant" social class, in which father's and mother's classes are given equal weight in determining household class (Erikson 1984). We use father's class as our operationalization because mothers in the earlier period who were in the labor force were more likely to be positively selected than mothers in the later period, which potentially introduces a bias when comparing the periods.

7 An alternative approach would be to examine mobility between occupations, rather than classes, in order to map out patterns of microclass mobility (Weeden and Grusky 2005; Jonsson et al. 2009). This would have been desirable, given the importance of microclass mobility in processes of intergenerational inheritance, but unfortunately our data are too sparse to allow us to consider such an approach.

8 Models were fitted using LEM (Vermunt 1997).

9 The reduction in G2 between models 2 and 3 is 83.3 for 25 degrees of freedom ( $p<0.01)$.

10 We exclude from the analysis all of those individuals with origins or destinations in the agricultural sector (i.e., those in the "self-employed farmers" and "farm labor" categories of the 10-class EGP classification), and given the differing importance of agricultural occupations for men and women, we carry out additional tests that account for gender differences. Excluding the agricultural sector, the male Unidiff coefficient is essentially unchanged (at 1.34), while the female coefficient is slightly increased (to 1.44).

11 The "aged in" cohort from the second time period is matched to a cohort of people 25 to 33 years of age in the first period. The "aged out" cohort from the first time period is matched to a cohort of people 56 to 69 years of age in the second period. 
12 The socioeconomic gradient term was measured using the average ISEI values for the EGP classes; the ISCO88 codes were assigned ISEI values using the Stata add-on isko.

13 Note that the two parameters are not measured on the same scale. We present both in the same figure because this makes it possible to easily observe and compare the patterns of the two sets of coefficients across countries.

14 The European Bank for Reconstruction and Development (EBRD) transition index tables can be accessed at: http://www.ebrd.com/what-we-do/economic-research-anddata/data/forecasts-macro-data-transition-indicators.html.

15 A table of insignificant correlation coefficients is available from the authors on request. We have also conducted more formal tests by including country-level measures in the log-linear models; the results again confirmed that these measures had little explanatory power.

\section{References}

Bell, Daniel. 1973. The Coming of Post-Industrial Society. A Venture in Social Forecasting. London: Heinemann.

Breen, Richard. 2004a. "Statistical Methods of Mobility Research." Pp. 17-37 in Social Mobility in Europe, edited by R. Breen. Oxford: Oxford University Press. https://doi .org/10. 1093/0199258457.003.0002

Breen, Richard. (ed.) 2004b. Social Mobility in Europe. Oxford: Oxford University Press.

Breen, Richard. 2010. "Social Mobility and Equality of Opportunity." The Economic and Social Review 41: 413-28.

Breen, Richard, and Jan O. Jonsson. 2005. “Inequality of Opportunity in Comparative Perspective: Recent Research on Educational Attainment and Social Mobility." Annual Review of Sociology 31: 223-43. https : //doi.org/10.1146/annurev. soc.31.041304.122232

Breen, Richard, and Ruud Luijkx. 2004. "Social Mobility in Europe Between 1970 and 2000." Pp. 37-76 in Social Mobility in Europe, edited by R. Breen. Oxford: Oxford University Press. https://doi.org/10.1093/0199258457.003.0003

Bukodi, Erzsébet, and John H. Goldthorpe. 2010. "Market versus Meritocracy: Hungary as a Critical Case." European Sociological Review, 26: 655-74. https://doi.org/10.1093/esr/ jсp043

Cao, Yang, and Victor G. Nee. 2000. “Comment: Controversies and Evidence in the Market Transition Debate." American Journal of Sociology 105: 1175-88. https://doi.org/10. $1086 / 210402$

Chetty, Raj, Nathaniel Hendren, Patrick Kline, Emmanuel Saez, and Nicholas Turner. 2014. "Is the United States Still a Land of Opportunity? Recent Trends in Intergenerational Mobility." NBER Working Paper No. 19844.

Erikson, Robert. 1984. "Social Class of Men, Women and Families." Sociology 18: 500-514. https://doi.org/10.1177/0038038584018004003

Erikson, Robert, and John H. Goldthorpe. 1992. The Constant Flux. A Study of Class Mobility in Industrial Societies. Oxford: Clarendon Press. https://doi .org/10.2307/589335

Erikson, Robert, John H. Goldthorpe, and Lucienne Portocarero. 1979. "Intergenerational Class Mobility in Three Western European Societies: England, France and Sweden." British Journal of Sociology 33: 1-34. 
Evans, Geoffrey. 1997. "Class inequality and the formation of political interests in Eastern Europe." European Journal of Sociology 38: 17-44. https://doi.org/10.1017/ S0003975600006949

Evans, Geoffrey. 2006. "The Social Bases of Political Divisions in Post-Communist Eastern Europe." Annual Review of Sociology 32: 245-70. https://doi.org/10.1146/annurev . soc. 32.061604 .123144

Evans, Geoffrey, and Colin Mills. 1999. "Are there Classes in Post-Communist Societies? A New Approach to Identifying Class Structure." Sociology 33: 23-46.

Evans, Geoffrey, Stephen Whitefield, Anthony F. Heath, and Clive Payne. 1993. Emerging Forms of Political Representation and Participation in Eastern Europe. Economic and Social Research Council, UK.

Ganzeboom, Harry B.G., Ruud Luijkx, and Donald J. Treiman. 1989. "Intergenerational Class Mobility in Comparative Perspective." Research in Social Stratification and Mobility 8: 3-79.

Ganzeboom, Harry B.G., Donald J. Treiman, and Wout C. Ultee. 1991. "Comparative Intergenerational Stratification Research: Three Generations and Beyond." Annual Review of Sociology 17: 277-302. https://doi .org/10.1146/annurev . so.17.080191.001425

Gerber Theodore P., and Michael Hout. 1998. "More Shock Than Therapy: Market Transition, Employment, and Income in Russia, 1991-1995." American Journal of Sociology 104: 1-50. https://doi.org/10.1086/210001

Gerber, Theodore P. 2002. "Structural Change and Post-Socialist Stratification: Labor Market Transitions in Contemporary Russia." American Sociological Review 67: 629-659. https : //doi.org/10.2307/3088910

Gerber, Theodore P., and Michael Hout. 2004. “Tightening Up: Declining Class Mobility during Russia's Market Transition." American Sociological Review 65: 677-703. https: //doi.org/10.1177/000312240406900504

Goldthorpe, John H. 1996. "Problems of 'Meritocracy'." Pp. 255-287 in Can Education be Equalized? The Swedish Case in Comparative Perspective, edited by R. Erikson and J.O. Jonsson. Boulder, CO: Westview Press.

Goldthorpe, John H., and Michelle Jackson. 2008. "Problems of an Education-Based Meritocracy," in A. Lareau and D. Conley (eds.) Social Class. How Does it Work? New York: Russell Sage Foundation Press.

Grusky, David B., and Robert M. Hauser. 1984. "Comparative Social Mobility Revisited: Models of Convergence and Divergence in Sixteen Countries." American Sociological Review 49: 19-38. https://doi.org/10.2307/2095555

Hanley, Eric, and Matthew McKeever. 1997. "The Persistence of Educational Inequalities in State-Socialist Hungary: Trajectory-Maintenance." Sociology of Education 70: 1-18. https://doi.org/10.2307/2673189

Heyns, Barbara. 2005. "Emerging Inequalities in Central and Eastern Europe." Annual Review of Sociology 31:163-97 https : //doi .org/10.1146/annurev . soc . 30.012703.110637

Hoffman, Erik P., and Robbin F. Laird. 1982. The Politics of Economic Modernization in the Soviet Union. Ithaca, NY: Cornell University Press.

Hout, Michael. 1988. "More Universalism and Less Structural Mobility: The American Occupational Structure in the 1980s." American Journal of Sociology 93: 1358-1400. https : //doi.org/10.1086/228904

Jonsson, Jan O., David B. Grusky, Matthew Di Carlo, Reinhard Pollak, and Mary C. Brinton. 2009. "Micro-Class Mobility: Social Reproduction in Four Countries." American Journal of Sociology 114: 977-1036. https : //doi .org/10.1086/596566 
Jonsson, Jan O., David B. Grusky, Reinhard Pollak, Matthew Di Carlo, and Carina Mood. 2011. "Occupations and Social Mobility: Gradational, Big Class, and Micro-class Reproduction in Comparative Perspective." Pp. 139-171 in Persistence, Privilege, and Parenting: The Comparative Study of Intergenerational Mobility, edited by Robert Erikson, Markus Jannti, and Timothy Smeeding. New York: Russell Sage Foundation.

Kerr, Clark. 1983. The Future of Industrial Societies: Convergence or Continuing Diversity? Cambridge, MA: Harvard University Press. https : //doi .org/10.4159/harvard. 9780674497627

Kolosi, Tamas. 1988. "Stratification and Social Structure in Hungary." Annual Review of Sociology 14: 405-19. https://doi.org/10.1146/annurev . so.14.080188.002201

Konrad, Georg, and Ivan Szelenyi. 1979. The Intellectuals on the Road to Class Power. New York: Harcourt Brace Jovanovich.

Lipset, Seymour M., and Richard B. Dobson. 1973. "Social Stratification and Sociology in the Soviet Union." Survey 19: 114-85.

Loveless, Matthew. 2009. EUREQUAL 1993-2007 Survey Codebook and Questionnaire. University of Oxford.

Mach, Bogdan W. 2004. "Intergenerational Mobility in Poland: 1972-88-94". Pp. 269286 in Social Mobility in Europe, edited by R. Breen. Oxford: Oxford University Press. https://doi.org/10.1093/0199258457.003.0011

Marshall, Gordon, Svetlana Sydorenko, and Stephen Roberts. 1995. "Intergenerational Social Mobility in Communist Russia." Work Employment and Society 9: 1-27. https: //doi.org/10.1177/0950017095009001002

Mateju, Petr. 1993. "Who Won and Who Lost in a Socialist Redistribution in Czechoslovakia?" Pp. 251-71 in Persistent Inequality: Changing Educational Attainment in Thirteen Countries, edited by Y. Shavit and H.-P. Blossfeld. Boulder CO: Westview Press.

Milanovic, Branko. 1998. Income, Inequality and Poverty during the Transition from Planned to Market Economy. Washington, D.C: World Bank.

Mitnik, Pablo A., Erin Cumberworth, and David B. Grusky. 2016. "Social Mobility in a High-Inequality Regime." The ANNALS of the American Academy of Political and Social Science 663: 140-184. https://doi .org/10.1177/0002716215596971

Mitra, Pradeep. 2008. Innovation, Inclusion and Integration. From Transition to Convergence in Eastern Europe and the Former Soviet Union. Washington, D.C.: World Bank. https: //doi.org/10.1596/978-0-8213-7538-9

Nee, Victor. 1989. "A Theory of Market Transition: From Redistribution to Markets in State Socialism." American Sociological Review 54: 663-681. https ://doi .org/10. 2307/ 2117747

Nee, Victor. 1996. "The Emergence of a Market Society: Changing Mechanisms of Stratification in China." American Journal of Sociology 101: 908-49. https://doi .org/10.1086/ 230784

Nee, Victor, and Rebecca Matthews. 1996. "Market Transition and Societal Transformation in Reforming State Socialism." Annual Review of Sociology 22: 401-435. https : //doi .org/ 10.1146/annurev.soc.22.1.401

Ossowski, Stanislaw. 1963. Class Structure in the Social Consciousness. New York: Free Press.

Parkin, Frank. 1971. Class Inequality and Political Order: Social Stratification in Capitalist and Communist Societies. London: MacGibbon and Kee. 
Pfeffer, Fabian T., and Florian Hertel. 2015. "How has Educational Expansion shaped Social Mobility Trends in the United States?" Social Forces, 94(1): 143-180. https ://doi .org/10. $1093 /$ sf /sov045

Raftery, Adrian E. 1995. "Bayesian Model Selection in Social Research." Sociological Methodology 25:111-63. https://doi .org/10.2307/271063

Rivera, Lauren. 2015. Pedigree: How Elite Students Get Elite Jobs. Princeton, NJ: Princeton University Press. https://doi .org/10.1515/9781400865895

Róbert, Péter, and Erzsébet Bukodi. 2004. “Changes in Intergenerational Class Mobility in Hungary, 1973-2000". Pp. 287-314 in Social Mobility in Europe, edited by R. Breen. Oxford: Oxford University Press. https://doi.org/10.1093/0199258457.003.0012

Strmiska, Zdenek. 1987. "Political Power and Social Inequality." Pp. 342-378 in Equality and Inequality in Eastern Europe, edited by P. Kende and Z. Strmiska. Leamington Spa: Berg.

Swift, Adam. 2004. "Would Perfect Mobility be Perfect?" European Sociological Review 20: 1-11. https://doi.org/10.1093/esr/20.1.1

Szelenyi, Ivan, and Eric Kostello. 1996. “The Market Transition Debate: Toward a Synthesis?" American Journal of Sociology 101: 1082-1096. https://doi .org/10. 1086/230791

Szelenyi, Szonja. 1998. Equality by Design: The Grand Experiment in Destratification in Socialist Hungary. Stanford, CA: Stanford University Press.

Treiman, Donald J. 1970. "Industrialization and Social Stratification." Sociological Inquiry 40: 207-234. https://doi.org/10.1111/j.1475-682X.1970.tb01009.x

Vermunt, Jeroen K. 1997. LEM 1.0: A General Program for the Analysis of Categorical Data. Tilburg: Tilburg University.

Walder, Andrew. 1996. "Markets and Inequality in Transitional Economies: Toward Testable Theories." American Journal of Sociology 101: 1060-1073. https://doi.org/10.1086/ 230789

Weeden, Kim, and David B. Grusky. 2005. "The Case for a New Class Map." American Journal of Sociology 111: 141-212. https : //doi .org/10.1086/428815

Wesolowski, Wlodzimierz. [1966] 1977. Classes, Strata and Power. [Translated by G. Kolankiewicz]. London: Routledge Kegan Paul.

Whitefield, Stephen, and Geoffrey Evans. 2007. EUREQUAL 2007: Design, Data Description and Documentation. Oxford University.

Wong, Raymond Sin-Kwok, and Robert M. Hauser. 1992. “Trends in Occupational Mobility in Hungary Under Socialism." Social Science Research 21: 419-44. https : //doi .org/10. 1016/0049-089X (92) 90005-2

World Bank. 2002. Transition. The First Ten Years. Analysis and Lessons for Eastern Europe and the Former Soviet Union. Washington, D.C.: The World Bank.

World Bank. 2008. Unleashing Prosperity. Productivity Growth in Eastern Europe and the Former Soviet Union. Washington, D.C.: The World Bank.

Xie, Yu. 1992. “The Log-Multiplicative Layer Effect Model for Comparing Mobility Tables." American Sociological Review 57: 380-395. https : //doi .org/10.2307/2096242

Xie, Yu, and Alexandra Killewald. 2013. "Intergenerational Occupational Mobility in Great Britain and the United States Since 1850: Comment." American Economic Review 103(5):2003-2020. https://doi .org/10.1257/aer.103.5.2003

Yastrebov, Gordey. 2016. "Intergenerational Social Mobility in Soviet and Post-Soviet Russia." Working paper series of National Research University Higher School of Economics, Moscow, WP BRP 69/SOC/2016. 
Acknowledgements: We thank John Goldthorpe, David Grusky, Ruud Luijkx, Kenneth MacDonald, the Sociological Science reviewers, and Kim Weeden for their very helpful comments and advice.

Michelle Jackson: Department of Sociology, Stanford University.

E-mail: mvjsoc@stanford.edu.

Geoffrey Evans: Nuffield College, University of Oxford.

E-mail: geoffrey.evans@nuffield.ox.ac.uk. 